This item was submitted to Loughborough's Research Repository by the author.

Items in Figshare are protected by copyright, with all rights reserved, unless otherwise indicated.

\title{
Service Blueprint for Sustainable Business Model Evaluation
}

PLEASE CITE THE PUBLISHED VERSION

https://designinnovationmanagement.com/pub/adim2019_proceedings.pdf

PUBLISHER

Design Management Academy

VERSION

AM (Accepted Manuscript)

PUBLISHER STATEMENT

This is an Open Access Article. It is published under the Creative Commons Attribution-NonCommercialShareAlike 4.0 International (CC BY NC SA). Full details of this licence are available at: https://creativecommons.org/licenses/by-nc-sa/4.0/

\section{LICENCE}

CC BY-NC-SA 4.0

\section{REPOSITORY RECORD}

Cheung, Cheryl, Ksenija Kuzmina, and Sharon Prendeville. 2019. "Service Blueprint for Sustainable Business Model Evaluation". figshare. https://hdl.handle.net/2134/9785918.v1. 


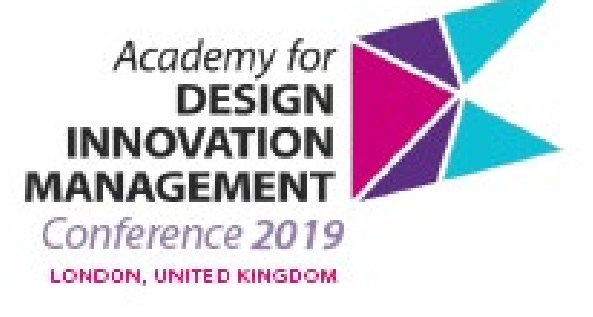

\title{
Service Blueprint for Sustainable Business Model Evaluation
}

\author{
CHEUNG Sau Ching Cheryl*, KUZMINA Ksenija and PRENDEVILLE Sharon \\ Loughborough University, London \\ * corresponding author e-mail: c.cheung@lboro.ac.uk
}

\begin{abstract}
The adverse societal impacts caused by sharing mobility - a form of service-based sustainable business model innovations, showed that operation activities and managerial practices impact heavily on the sustainable value of a service offering. To identify how new service development (NSD) activities can better support the proposed service offering for sustainability, evaluating sustainability of service operations is needed. This study draws learnings from service design, product-service system and sustainable innovation research streams, to build sustainability evaluation framework into service blueprint. Six expertinterviews and two mobility case studies were developed, to illustrate service blueprint's capability in mapping sustainability input and benefits created during NSD and service operation activities. Results revealed a) the shift from using sustainable 'value' to 'benefits' concept in service operation evaluation, b) the public-private collaboration dilemma and c) the agile NSD and sustainable innovation incompatibility. This paper aims to offer a springboard for practitioners and researchers to uncover compelling insights, discuss latest service design developments, and envision future directions for integrating sustainability into service-based business model innovation.
\end{abstract}

Keywords: Service Innovation, Service Design, Sustainable Business Model Innovation, Sustainable Value Co-creation, Sustainability Evaluation Tool

\section{Introduction}

As environment and resource risk continue to challenge the world, a significant number of interests turn to how sustainable innovation (SI) drives economic growth while improving environmental and social performance (Boon et al., 2013; Charter and Clark, 2007). Recent years, rising service-based innovations have dominated the sustainable innovation in mobility activities, providing mobility services through collaborative consumption (Botsman and Roger, 2010; Morozov, 2013). Based on service-dominant logic, services are value networks (Vargo and Lusch, 2006) that presuppose social actors to be integral to the processes of service production as well as consumption. Thus, this brings to question how the implementation of collaborative organisational processes, activities and operations, impacts the proposed service offering and experience (den Hertog et al., 2010; Janssen et al., 2015). It is also unclear, how actors within a service operation co-create sustainable values in the delivery of service offering (Boon and Mendoza, 2010).

This gap is particularly visible in the mobility sector with the rise of sharing economy (e.g. peer-topeer ridesharing and delivery). While the design of mobility service offering utilises assets through collaborative consumption, there is more and more attention drawn to rideshare services' unclear 
management policy of workers' rights and responsibilities, as well as the commoditization in aspect of life. With the blurry definition of collaborator, the rise of rideshare became controversial and caused adverse societal impact in the service operation (Cohen and Kietzmann, 2014; Schofield, 2014; Morozov, 2013). Since sustainable innovation (SI) refers to product, processes or services that increase Triple Bottom Line (TBL) economic, social and environmental values in their production and consumption activities (Charter et al., 2008; Charter and Clark, 2007; Elkington, 1998), there is a need for evaluating the mobility service operation activities to identify how mobility service development process can be improved to better support its' proposed service offering for sustainability. This raises a question of how existing sustainability evaluation tools address and help service innovation and its' involved actors to integrate sustainability at every stage of the new service development (NSD) and service operation journey.

In the existing literature, sustainability, service and innovation have been the subject of much research and discussion (Calabrese et al., 2018; Chou, Chen and Conley, 2012; Vezzoli et al., 2015; Martin, 2016; Botsman and Roger, 2010; Cohen and Kietzmann, 2014; Yu and Sangiorgi., 2018), yet to the best of our knowledge no research has focused on how service design evaluates service actors' co-creation of sustainable values in NSD and service operation. Amongst the limited sustainability evaluation tools developed in the past literature, relevant literature scattered across three streams of research in service design, product-service system (PSS) and sustainable innovation (SI), focuses on different sustainability and innovation dimensions (Calabrese et al., 2018). The observed phenomenon within mobility sector points out an emerging field of service innovation for sustainability, which embraces multi-dimensional innovation across system, design, technology, organisation and customer in all three streams of research (den Hertog, 2000). Sustainability evaluation within service innovation in mobility needs to draw learnings from the three streams, develop practical tools that holistically address TBL sustainability and support the maturity of service innovation development for sustainability.

In this study, we investigate the potential of using service design's operational planning tool to evaluate service operation activities against proposed service offering for sustainability. We first review the service design and innovation literature, sustainable value creation and dynamic capabilities for sustainable business model innovation. Concept of uncaptured sustainable value within PSS stream (Yang et al., 2017) and the collaboration principles within SI stream (Curșeu and Schruijer, 2017) are reviewed, integrated into service operation planning tool - service blueprint and evaluated with industry experts for its' usability in practice. Then, the revised sustainability evaluation service blueprint is applied to two mobility case studies, to identify insights of what operation activities offer opportunities to innovate for sustainability. The results further conclude with implications in practice when using service design to facilitate sustainable values creation in service development process (Yu and Sangiorgi., 2018).

\section{Service Design for Sustainable Innovation}

In recent years, more and more sustainable business model innovations focus on providing services, in order to capture sustainable value through collaborative consumption (Cohen and Kietzmann, 2014). This view revealed that service is understood as a perspective on business, instead of simply a form of goods ( Edvardsson, Gustafsson, and Roos 2005; Vargo and Lusch 2004).Therefore, a rising Service Design logic is being considered as Sl's design and management strategy for its' suitability to deal with complex situation with multiple actors involved (Chou, Chen and Conley, 2012; Baldassarre et al., 2017; Prendeville and Bocken, 2017; Tukker, 2015). Service design is rooted in human-centred design, focus on problem solving with iterative design process (Stickdorn, Schneider and Andrews, 2011). Its' design process keeps customer journey at the heart and looks at end-to-end holistic service operation, as well as front and back service support at the same time (Sangiorgi et al., 2012). Through engaging actors with empathic design methods, service design discovers, identifies and addresses their concerns with service design and process reconfiguration (Segelström, 2013;

Schmiedgen and Management, 2011) 
Numbers of widely-used and effective tools have been developed to help service designers to sense make, discover and conceptualise new perspective on a particular service. In particular, service operation planning tool - service blueprint visualises a service user's experiences through different touchpoints, details their service interaction with front and back service support throughout the end-to-end journey (Stickdorn, Schneider and Andrews, 2011). It focuses on visualising user-interaction, relationship analysis and service experiences through multi-actors perspectives. Revealing the fundamental service design thinking to sensemake, organise and reimagine complicated relationships and interaction within a particular service, for an intended outcome (Dorst, 2015; Verganti, 2011, 2014). Through visualisation of service blueprint, it maps out how actors within a particular service interact. This means service blueprint key contribution is providing visibility on complex service operations. Therefore, focusing service operation visualisation against sustainability evaluation requires a framework for evaluating service actors' sustainable value co-creation during operation. This draws the investigation of sustainability evaluation to product-service system and sustainable innovation literature, in order to discuss and integrate learnings into the development of sustainability evaluation for service operations.

\section{Existing Sustainability Evaluation Tools}

In the search of existing sustainability evaluation tools, we have found that many tools focus on evaluating the design of sustainable business model Innovation (BMI), its' value proposition and its' innovation process (Bocken et al., 2013; Evans, Rana, and Short 2014; Yang et al., 2017). Value mapping tool (Bocken et al., 2013; Evans, Rana, and Short 2014) evaluate BMI sustainability issues against internal and external stakeholders such as environment and society. Sustainable value analysis tool (Yang et al., 2017) focused on identifying the uncaptured sustainable values for stakeholders across the product life cycle, then translate them into opportunities for Innovation reconfiguration. These tools focus on analysing relationships and value exchange within a BMI, in order to improve value creation at the design and innovation process of BMI. Through the BMI perspective, these tools evaluate on the concept of how sustainable value can be delivered through a business, yet the perceived limitation of BMI perspective lies in its' capability to translate into practical business action (Prendeville and Bocken, 2017). This implies that these sustainability evaluation tools also have the limitation on evaluating the organisational and managerial sustainability impact in practice.

Amongst the two tools mentioned, sustainable value analysis tool (Yang et al., 2017) incorporates the perspective of product service systems (PSS) and establishes its' evaluation on product lifecycle, in order to bridge the evaluation gap between design concept of BMI and PSS development process. However, due to a number of factors, such as internal culture, organisational capabilities and the demand in multiple actors collaboration, PSS perspective still has its presupposed barrier to holistically evaluate the phenomenon of service innovation in the sharing economy (Tukker, 2015; Vezzoli et al., 2015). The comparison of these core concepts revealed the need to examine the practical organisational and managerial capabilities, in order to address the sustainability impact incurred in the service operation.

\section{Organisational and Managerial Capabilities for Sustainable Value Creation}

The importance of practical organisational and managerial capabilities is well defined in the literature of SI. According to Inigo et al. (2017), these are core-elements to co-creating social and environmental sustainable values in operations, as well as creating successful BMI (Mezger, 2014). In particular, the organisational capabilities needed for sustainable value creation involves understanding their own interaction with external set of activities in knowledge creation, stakeholder engagement and technological innovation, then utilising them with their own internal resources. This outlined two types of practical organisational and managerial capabilities, see table 1 :

Table 1. Organisational and Managerial Capabilities for Sustainable Value Creation (Inigo et al., 2017)

Organisational and Managerial Capabilities for Sustainable Value Creation

Capability in collaborating for sustainability
Close stakeholder dialogue and community participation leads to continuous learning and adaptation to the dynamics of TBL sustainable value creation 
Capability in transforming operational activities for sustainability
Technological transformation of organisational structure and system activities creates TBL sustainability values for social actors involved

This draws the focus on investigating what's required for organisations to develop collaboration and transform operational activities for creating TBL sustainability values.

\section{Capability in Collaborating for Sustainability}

Achieving SI requires the collaboration between social actors involved in the particular innovation (Boons and Mendoza, 2010). Collaboration with multiparty enrich the knowledge pool and the comprehensiveness of sustainable value creation process. Through the collaborative process, actors explore their interdependencies, use their expertise and knowledge to integrate and influence the sustainability decision making outcome (Curșeu and Schruijer, 2017). It was discovered that the decision quality increases when social actors' diversity of interests is expressed through information sharing and exploration, while decision quality was compromised when social actors' diversity of interests was not acknowledged in the value creation process (Fadeeva, 2005, p173). Therefore, collaboration for sustainability considers the design of the internal structure with stakeholder interactions (Inogo el al., 2017). In which, scholars of stakeholder engagement in sustainability suggested three constructive collaboration principles that are crucial to capture actors' interest diversity and foster inclusive and sustainable value creation environment, see table 2 (Cox et al., 2010; Curșeu and Schruijer, 2017).

Table 2. Constructive Collaboration Principles for Sustainable Value Creation (Curșeu and Schruijer, 2017)

Constructive Collaboration Example/Prompts
Principles

Inclusive Stakeholder Selection Are there tools in place to remove power disparity and assist peripheral stakeholders to voice their concern, in order to avoid biased selection of particular stakeholders and create sufficient representation of power dynamics between multi-stakeholders?

Normative System for

Collaboration

Are there ground rules to build constructive task conflicts and engage in healthy debates, for enabling comprehensive problem formulation and cross-understanding of diverse viewpoints?

Process Consultation

Are there tasks consultation with multi-stakeholder during the process, to stimulate the emergence of trust, psychological safety and prevent collusive dynamics?

\section{Capability of TBL Sustainable Value Creation in Operational Activities}

On the other side, achieving technological sustainability transformation in organisational structure and system activities, consider how to harness the uncaptured TBL values within product lifecycle (Chou, Chen and Conley, 2012; Elkington,1994; Plepys et al., 2015). This implies that open and uncaptured perspective is crucial for sensemaking sustainability in product service lifecycle (Rauter, Vorbach and Baumgartner, 2017). Through focusing on the negative form of values, a reversal thinking was suggested, shaping focus for conducting complex sustainability research (van Veggel, 2005). It was suggested that the four forms of uncaptured values (Yang, 2016; Yang et al., 2017): value missed, value surplus, value destroyed and value absence can be utilised to discover, identify and articulate the comprehensive TBL values, which are not currently captured in the business model and its' product service lifecycle, see table 3 :

Table 3. Adopted from Four Form of Value Uncaptured of Yang et al. (2016)

$$
\text { Definition Example/ Prompts }
$$




\begin{tabular}{lll}
$\begin{array}{l}\text { Value } \\
\text { Missed }\end{array}$ & $\begin{array}{l}\text { Something exists that } \\
\text { is not exploited. }\end{array}$ & $\begin{array}{l}\text { Are there tangible or intangible resources that are underutilized? (e.g. } \\
\text { capital assets or human resources?) } \\
\text { Is the business creating value in some form that it is failing to capture? } \\
\text { (e.g. through the better use of data to enhance service?) }\end{array}$ \\
\hline $\begin{array}{lll}\text { Value } \\
\text { Surplus }\end{array}$ & $\begin{array}{l}\text { Something exists that } \\
\text { is not required. }\end{array}$ & $\begin{array}{l}\text { Are there excessive benefits? (e.g. overproduction, excessive service } \\
\text { functionality?) }\end{array}$ \\
\hline $\begin{array}{l}\text { Value } \\
\text { Destroyed }\end{array}$ & $\begin{array}{l}\text { Something exists that } \\
\text { undermines value. }\end{array}$ & $\begin{array}{l}\text {. What are the negative outcomes of the business at each lifecycle stage? } \\
\text { Is there a potential or perceived risk of value being destroyed by } \\
\text { continuing customary practices? (e.g. a risk of time to market?) }\end{array}$ \\
\hline $\begin{array}{l}\text { Value } \\
\text { Absence }\end{array}$ & $\begin{array}{l}\text { Something required } \\
\text { that does not exist. }\end{array}$ & $\begin{array}{l}\text { What tangible and intangible needs of the company and its stakeholders } \\
\text { have not been realized? }\end{array}$ \\
\hline
\end{tabular}

Through this identification process, organisation can transform the uncaptured TBL values and turn them into innovation opportunities. Yang et al. (2017) also used this uncaptured TBL values to develop Sustainability analysis tools (see figure 1), provided an effective step-by-step structure in analysing how captured and uncaptured TBL value incurred within the product life cycle. The step-by-step structure analyses value captured, then value uncaptured, for all stakeholders throughout the product life cycle. Through identifying the negative form of value, the analysis tool assists the discovery of new TBL value opportunities. It helps complex operations to take the initiative in understanding how their product life cycle can be optimised for sustainable value creation.

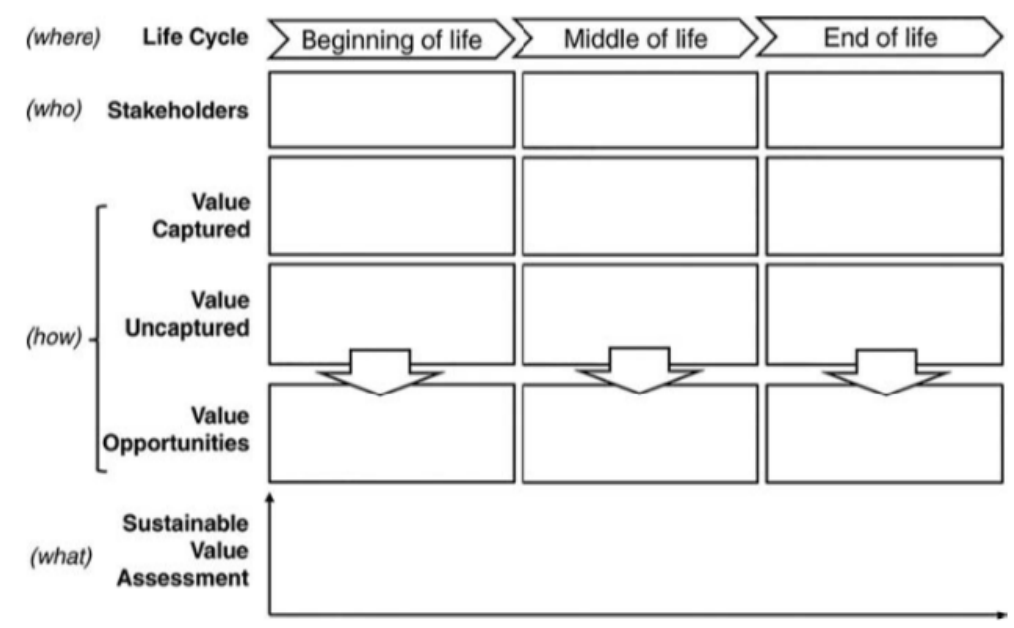

Figure 1. The Sustainable Value Analysis Tool (Yang et al., 2017)

\section{Preliminary Sustainability Evaluation Service Blueprint}

After the investigations above, we can see that achieving sustainable value creation in Service-Based Business Model Innovation requires not only the maturity in the operational and managerial capabilities. Most importantly, organisations need to understand the external environment of knowledge, stakeholder engagement, technologies and utilising them with internal resources for TBL sustainable value creation (Inigo et al., 2017). This points out the importance of sense making an organisation's design concept of BMI for sustainability, PSS development process and practical service operation. To do this, it is crucial to develop strategic and practical evaluative tool. A tool such as the service blueprint, which has capability in 1) providing visibility to the complex multi-actors service operations (Stickdorn, Schneider and Andrews, 2011); and the flexibility to sense make specific knowledge, such as 2) understanding the existing structure of stakeholder interaction during service operation, and 3) understanding the uncaptured and captured TBL values within existing product-service lifecycle (figure 2). Therefore, here we synthesise the literature findings and describe a preliminary sustainability evaluation service blueprint. 


\section{Identifying the New Service Development (NSD) and Service Operation process}

Since the aim of the blueprint was to evaluate how the service was iterated and developed throughout the NSD and service operation process. Therefore, identifying the process to be blueprinted was the first priority (Shostack, 1984). The investigation would start from specifying physical evidence (service experience lifecycle), where the aim is to understand what iterations the service experience lifecycle has gone through (e.g. alpha, beta, launched version). Then, it goes deeper to look at what interactions are needed both digital and physical that support the customer interactions in each of these development phase. when are they aware of this service? When do they join into test and feedback the product? And what are the relations between customers feedback and subsequent NSD activities?

\section{Criteria 1: Evaluating Collaboration for Sustainability}

As the blueprint develops, it revealed the different internal actors involved in the NSD activities. Therefore, it is also important to investigate who are the external actors that have been supporting the service development: How were they involved? What are the relations between external actors' feedback and subsequent NSD activities? The investigation of the above provided visibility to NSD activities, reveal silos and areas of opacity in existing service, as well as the complex and intricate relationships with different actors.

By evaluating how collaboration was conducted at each level and each step of the service operation, it allows us to analyse the comprehensiveness and the quality of the sustainable value creation process. It aims to identify whether there's a bias selection of stakeholders, there's a system for healthy debate and whether collaboration process was consulted with stakeholders to avoid collusive dynamics (Curșeu and Schruijer, 2017).

\section{Criteria 2: Evaluating TBL Sustainable Value Creation in the Operational Activities}

More importantly, this rich information enables the latter part of the blueprint to carry out sustainability evaluation against the exploited and unexploited TBL benefits. For example, one can specify how the service exploited TBL benefits in alpha version, which would be made comparable to the service's launched version. This then provide insights into whether NSD activities has been optimised for sustainable value creation.

By evaluating what uncaptured TBL values (value missed, value surplus, value destroyed and value absence) exist at each level and each step of the service operation, it allows us to determine whether there are activities underutilised in service operation; there are activities exist that do not align with TBL values; there are activities align with TBL values which was destroyed in the process of service operation; or there are activities that do not exist yet required, in order to align with TBL value creation in service operation (Yang et al., 2016).

With this thorough analysis, the blueprint then provide visibility towards what and how TBL values were created during NSD process and service operation. Enabling organisations to see the gap between design of service offering for sustainability and the delivery of sustainability during service operation, then reconfigure its' service operations' activities and managerial practice accordingly. This evaluation blueprint aims to function as the first step to sense making - internalising the environment of knowledge, stakeholder engagement, technologies of existing service for sustainable value creation (Inigo et al., 2017). 


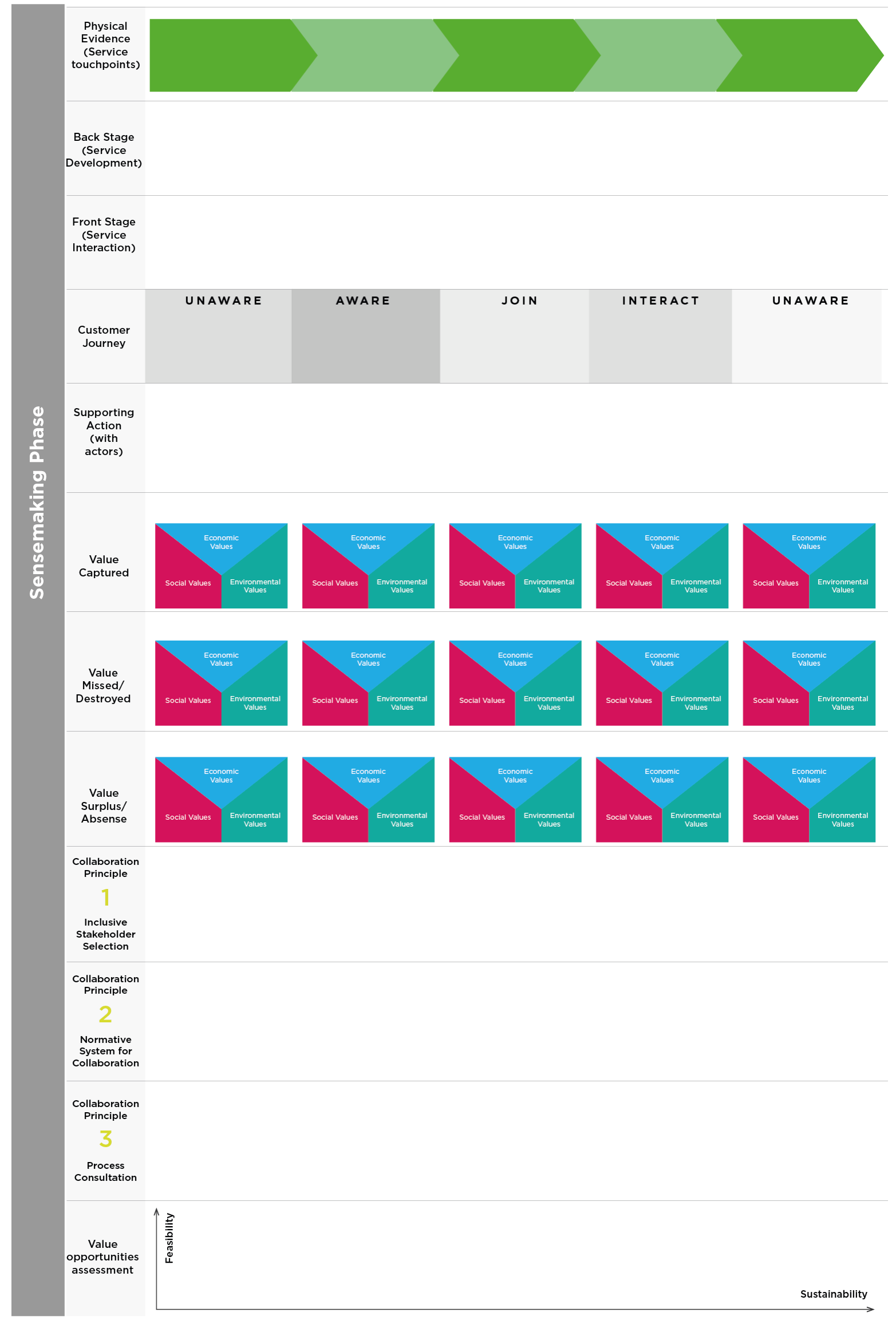

Figure 2. Preliminary Sustainability Evaluation Service Blueprint 


\section{Methods}

This research is exploratory and uses the literature review to generate a preliminary blueprint. To provide insights into the service innovation as sustainable BMI phenomenon, our research design involved six expertinterviews for preliminary blueprint validation and desk research to generate two case studies in mobility sector (Bailey, 2010; Yin, 2003). Furthermore, it explores the actual practicalities in using the synthesised blueprint. See process diagram (figure 3.) below for methods used in each stage of research:
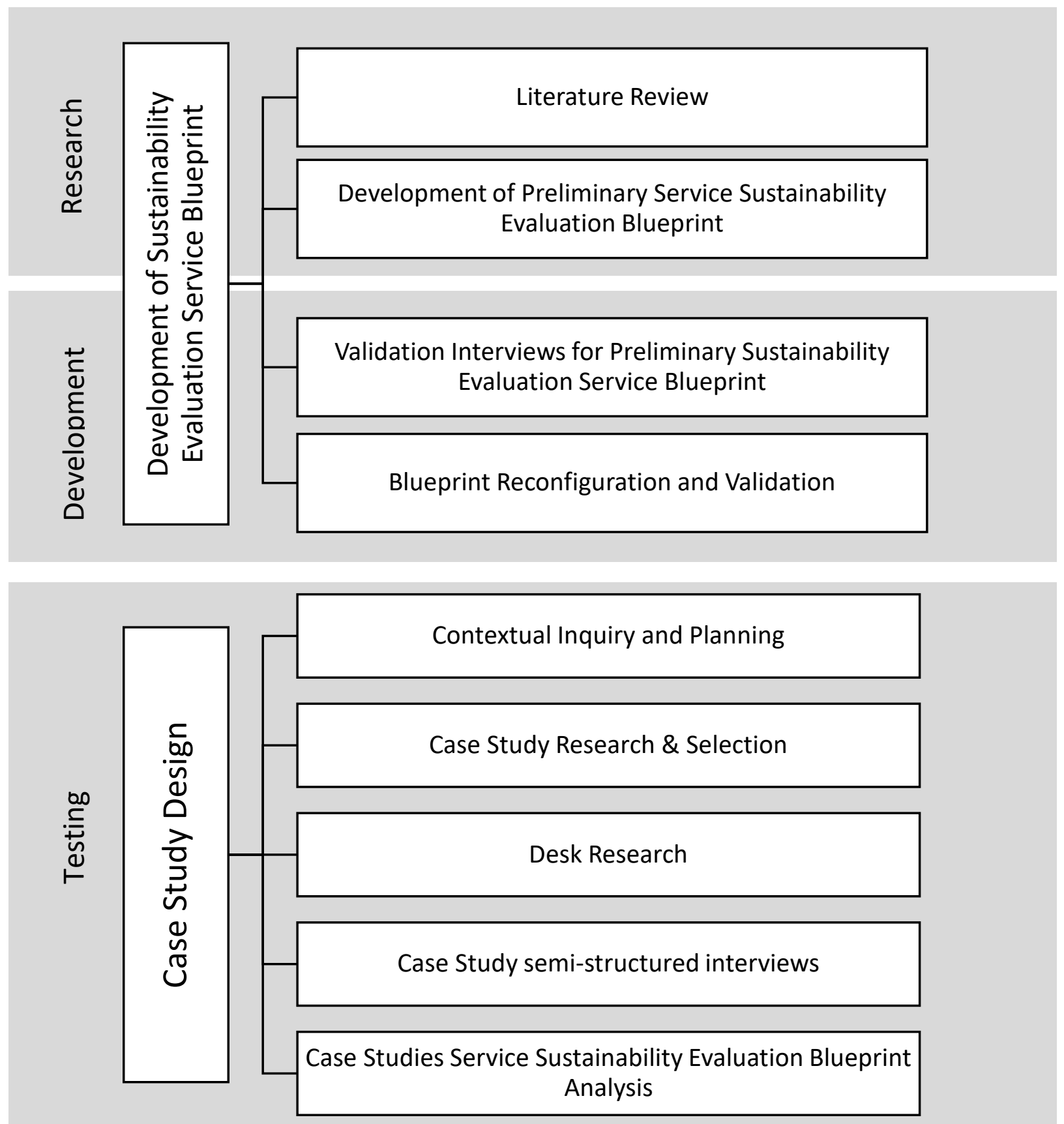


\section{Development of Sustainability Evaluation Service Blueprint}

A preliminary blueprint was synthesised from literature review of three research streams (service design, PSS and $\mathrm{SI}$ ). As literature review and contextual inquiry pointed out that sharing mobility services is a newly emerged phenomenon, sustainability evaluation service blueprint can potentially be used by actors involved in all three streams of research. Therefore, semi-structured interviews were conducted with six actors involved in service design, PSS and SI. Upon completion of blueprint evaluation and validation, contextual research and interview insights were drawn. As information was vast, applicable information were sorted into clear categories using an Affinity Diagram, which allows key feedback to be addressed and summarized for revising the blueprint, see process diagram (figure 3). Iterated blueprint (see figure 5) was updated after discussion and feedback from expert interviewees. To test the iterated blueprint, case study method is determined to be an appropriate method for explorative research and observing phenomenon (Bailey, 2010; Yin, 2003).

\section{Case Study Design}

Figure 3 specified the process of using case study method to test and demonstrate the Sustainability Evaluation Service Blueprint. An initial desk research was conducted to highlight mobility services in sharing economy as sustainable innovation phenomenon (Botsman and Roger, 2010; Hyard, 2013; Cohen and Kietzmann, 2014). Citymapper Smart Ride and Ford Chariot were selected based on the criteria developed under desk research of Sustainable Mobility in the UK (See Table 4). Industry related documents and reports were reviewed and studied to establish an understanding of UK share mobility service industry practice, goals and strategies. To understand how multi-party actors contribute in sharing mobility service as sustainable innovation phenomenon, three experts interviews were conducted to provide insight for the investigation.

Table 4. Criteria for Case Studies Selection

\begin{tabular}{ll}
\hline \multicolumn{1}{c}{ Criteria } & \multicolumn{1}{c}{ Determined by: } \\
\hline $\begin{array}{l}\text { Clear intend to develop disruptive } \\
\text { mobility innovation that meet TBL } \\
\text { values: }\end{array}$ & $\begin{array}{l}\text { Identifiable TBL values developed based on publications and recommendation by } \\
\text { experts. }\end{array}$ \\
\hline Social value & $\begin{array}{l}\text { Satisfy the essential mobility needs of the people through promoting equality use } \\
\text { of open data (Rose, 2017). }\end{array}$ \\
\hline Economic value & $\begin{array}{l}\text { Offers affordable, functional and efficient transport solutions that support } \\
\text { economic development (Chariot, 2018; Citymapper, 2018a). }\end{array}$ \\
\hline Environmental value & $\begin{array}{l}\text { Limits carbon emissions and pollutants through utilising assets and resources } \\
\text { (Chariot, 2018; Citymapper, 2018b). }\end{array}$ \\
\hline Accessibility & Observable to researcher - operates in London, UK \\
\hline
\end{tabular}

Two selected mobility case studies were mapped using the Iterated Sustainability Evaluation Service Blueprint. Data about case studies was collected via desk research and expert interviews with share mobility service actors. While this analysis is not intended to be exhaustive, it aimed to illustrate how service operation's TBL values can be visualised using the conceptual Sustainability Evaluation Service Blueprint.

\section{Limitations}

The synthesised blueprint was evaluated by a small study sample of participants and experts, where it may be limited to its diversity and bias. Furthermore, the analysis examined the concept of the blueprint through exploratory case study approach, where wide range of public documents, research, articles and interviews were reviewed to address the phenomenon (Yin, 2003). Yet, the effectiveness and contribution of the synthesised blueprint has not been evaluated, which pointed out potential areas for future work in this topic. 


\section{Results}

\section{Blueprint Iteration and Validation}

Thematic analysis was conducted using Affinity Diagram, where comments that are repeatedly mentioned by the experts during the interviews were written down on post-it notes, then sorted into different categories. Following this display of insights, key feedbacks could be identified:

1. Varied collaboration principles comments depending on actor's commercial and non-commercial industry nature

2. Time is a big concern for commercial actors to establish inclusive stakeholder selection and process consultation principles

3. Confusing language of 'value' in sustainable values concept and uncaptured value concept

4. Facilitation is key to establish normative system for collaboration

5. The preliminary sustainability evaluation service blueprint lack facilitating guidance

6. Contradictory comments in Inclusive stakeholder selection, where unexpected stakeholders delay timescale, but getting people involve is difficult

7. Tendency to select stakeholders based on running relationships and immediate network

The highlighted feedbacks above were particularly relevant in guiding the next stage of blueprint development. These feedbacks are categorised into the three themes below:

\section{Facilitation is key to service blueprint swim lanes, yet there's a lack of facilitative question and prompts}

The different terms of uncaptured values are difficult to understand and explain. As the 12 swim lanes investigations underlined the potential requirement of holding a series of stakeholder research workshops, to understand existing service, actors involved and how the collaboration was carried out. Therefore, interviewees suggested that plain English would be easier to understand. Also, facilitative questions linked to the swim lane would be preferable for facilitating workshops amongst actors (e.g. customers, front end staff, back end staff, external actors, etc). Interviewee commented:

'You only have that one opportunity in a workshop setting to get as much information as you need...you would want to plan for the entire facilitation, so you get what you want from them' (User Experience Designer, Commercial Design Consultancy).

Therefore, prompted questions are created for the reconfigured blueprint based on Yang et al. (2017) facilitative question, see table 5 .

\section{From Values to Uncaptured Inputs and TBL benefits}

Interviewees find the term value confusing between 'sustainable values' and 'uncaptured values'. Interviewee commented:

'I don't know whether this is personal aspiration values or organisational values?' (Consultancy Director, Commercial Sustainability Consultancy)

Therefore, the usage of value concept is in need of further analysis in discussion session, which lead to the iteration of terminology used in the blueprint, where the term 'value' in 'sustainable value' was simplified as 'benefits', and the term 'uncaptured value' was simplified to 'unexploited input'. During the interviews, it was also identified that interviewees did not understand the different terms of values until an illustrative example was given. Consequently, the relevant value swim lanes on the blueprint were adjusted with the language suggested by the interviewees, along with the prompt questions based on Yang et al. (2017), see table 5: 
Table 5. Iteration of Four Form of Value Uncaptured of Yang et al. (2017)

\begin{tabular}{|c|c|c|}
\hline Terms & Definition & Example/Prompts \\
\hline $\begin{array}{l}\text { Exploited input } \\
\text { (Captured Value) }\end{array}$ & $\begin{array}{l}\text { Something that has } \\
\text { created and improved } \\
\text { business economic } \\
\text { benefits. }\end{array}$ & $\begin{array}{l}\text { How have they exploited benefits from the business } \\
\text { operation process? }\end{array}$ \\
\hline $\begin{array}{l}\text { Insufficient Use of } \\
\text { Input } \\
\text { (Value Missed) }\end{array}$ & $\begin{array}{l}\text { Something exists that is } \\
\text { not exploited for } \\
\text { sustainability benefits. }\end{array}$ & $\begin{array}{l}\text { Are there tangible or intangible resources that are } \\
\text { underutilized? (e.g. capital assets or human resources?) } \\
\text { Is the business creating benefits in some form that it is } \\
\text { failing to capture? (e.g. through the better use of data } \\
\text { to enhance service?) }\end{array}$ \\
\hline $\begin{array}{l}\text { Excessive Input } \\
\text { (Value Surplus) }\end{array}$ & $\begin{array}{l}\text { Something exists that is } \\
\text { not required for } \\
\text { sustainability benefits. }\end{array}$ & $\begin{array}{l}\text { Are there excessive benefits? (e.g. overproduction, } \\
\text { excessive service functionality?) }\end{array}$ \\
\hline $\begin{array}{l}\text { Undermined Input } \\
\text { (Value Destroyed) }\end{array}$ & $\begin{array}{l}\text { Something exists that } \\
\text { undermines value for } \\
\text { sustainability benefits. }\end{array}$ & $\begin{array}{l}\text { What are the negative outcomes of the business at each } \\
\text { lifecycle stage? } \\
\text { Is there a potential or perceived risk of value being } \\
\text { destroyed by continuing customary practices? (e.g. a } \\
\text { risk of time to market?) }\end{array}$ \\
\hline $\begin{array}{l}\text { Required-but-Non- } \\
\text { existent Input } \\
\text { (Value Absence) }\end{array}$ & $\begin{array}{l}\text { Something required that } \\
\text { does not exist for } \\
\text { sustainability benefits. }\end{array}$ & $\begin{array}{l}\text { What tangible and intangible needs of the company and } \\
\text { its stakeholders have not been realized? }\end{array}$ \\
\hline $\begin{array}{l}\text { Identified Input } \\
\text { opportunities } \\
\text { (Value Opportunities) }\end{array}$ & $\begin{array}{l}\text { Something that has been } \\
\text { identified that can } \\
\text { improve business } \\
\text { sustainability benefits. }\end{array}$ & $\begin{array}{l}\text { How can insufficiently-use and needed input be } \\
\text { introduced and exploited? } \\
\text { How can undermined and excessive input be } \\
\text { eliminated? } \\
\text { What innovations could extend the exploited input in } \\
\text { new and radical ways? } \\
\text { How can greater economic, societal and environmental } \\
\text { benefits be captured from the existing business? } \\
\text { Where in the life cycle are there conflicts of interests } \\
\text { between stakeholders? How can they be resolved? }\end{array}$ \\
\hline
\end{tabular}

\section{Examination Needed for Collaboration Principles for Multi-Stakeholder}

Interviewees generally agreed facilitating multi-stakeholder collaborations required two of the collaboration principles - Inclusive stakeholder selection and normative system for collaboration. Process consultation, however received the most diverse comments. Commercial actors pointing out that most of their commercial partners rely on them for process, interviewee also commented that:

'I don't quite agree on this one, if we consult them on process, it will take a very long time...I think it is more of an academic thing' (Consultancy Director, Commercial Sustainability Consultancy).

However, public and independent actors are in favour of process consultation as a core principle and suggested that it is part of the best practice. Therefore, these diverse perspectives and viewpoints are in need for further examination, analysis and discussion through the case studies. 


\section{Iterated Sustainability Evaluation Service Blueprint}

Based on the key feedback and desk research, the preliminary blueprint (see figure 2) was revised, to accurately present the information that was needed. The revised Sustainability Evaluation Service Blueprint (see figure 5) outlined facilitating questions to assist the investigation for the 12 swim-lanes: the existing process, physical evidence of artefacts, front-end service interaction, back-end service development, supporting actors involved, exploited input, insufficient use of input, excessive input, undermined input, required-but-non-existent input, identified input opportunities and input opportunities assessment.

By specifying the exploited TBL benefits in different NSD stage, the blueprint then goes deeper to evaluate (criteria 2) whether the NSD activities have evidence of insufficiently used input (or other types of inputs) at one specific stage that could enhance TBL benefits? Then, it goes deeper into evaluating whether (criteria 1) there is a quality sustainable value creation process. For example, do the NSD activities have evidence of embedding the 3 sustainable collaboration principles at each stage?

These evaluations then provide means to the next swim lane - identified input opportunities, where facilitative question, such as 'How can undermined input be eliminated?', is given to stimulate insight generation for service sustainability configuration. The blueprint ends on input opportunity assessment swim lane, where a sustainability-feasibility matrix is given to facilitate the evaluation of which input opportunities have higher sustainability impact and higher feasibility?

The sustainability evaluation service blueprint is designed to be modular and facilitative tool, for service designer and service developer to 1) understand an existing service, 2) understand the actors involved in the NSD and 3) to improve the service sustainability by identifying sustainable collaboration principles and eliminating unexploited TBL inputs in existing service. 


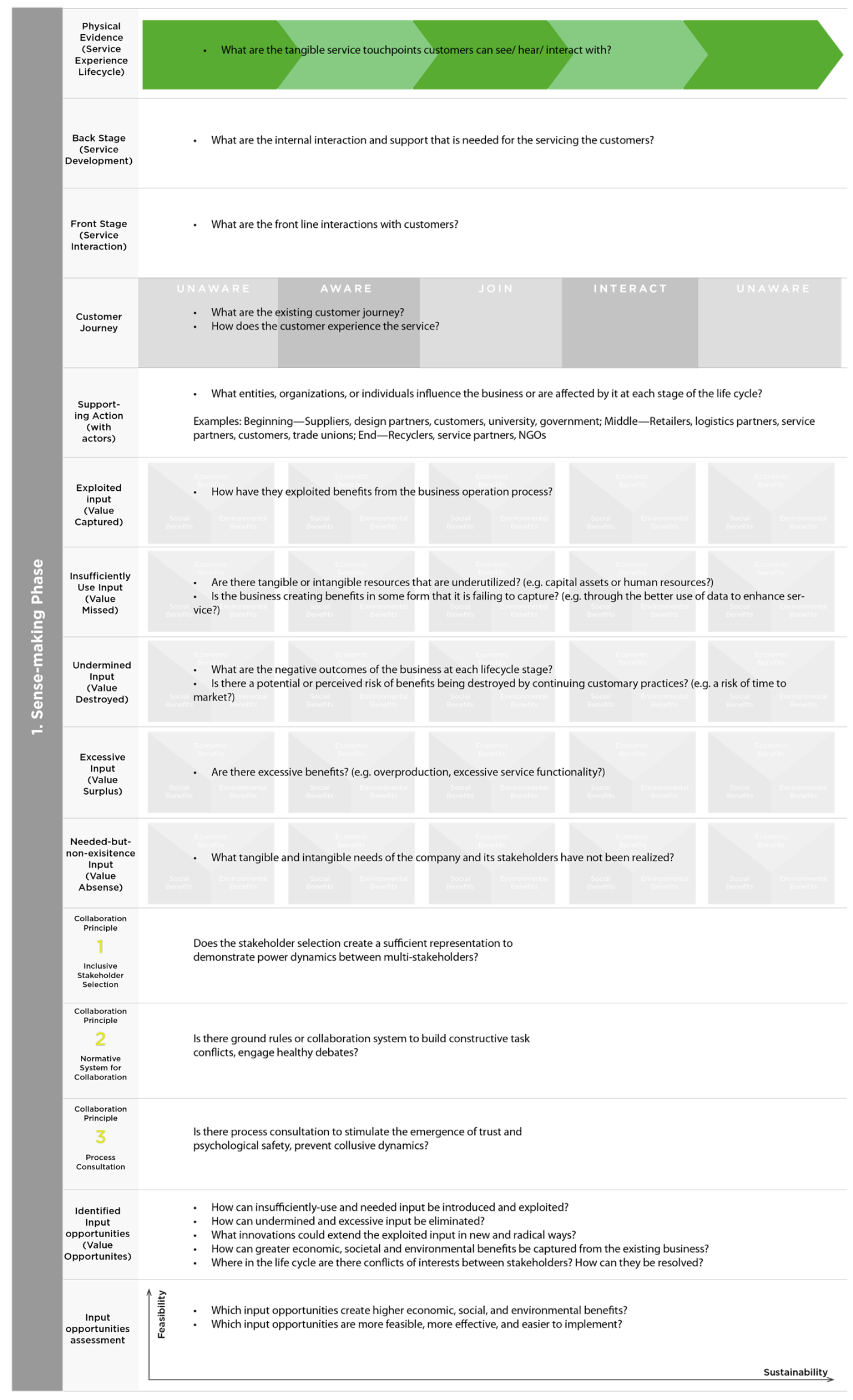

Figure 5. Iterated Sustainability Evaluation Service Blueprint 


\section{Testing Blueprint Through Case Studies}

Combined the results from desk research and interviews, two case studies - Citymapper Smart Ride and Ford Chariot Commuter bus were mapped against the iterated blueprint, followed by a cross case study analysis.

\section{Citymapper Smart Ride}

Table 6. Citymapper Smart Ride Operation Profile

Background:

Citymapper is an innovative transit and mapping service app that integrate open urban transport data and provide transit information to city users (Merlin and Eleni, 2018). This service provided Citymapper with insights on how public transport is supplied in an urban city like London. Therefore, Citymapper Smart Ride service was launched on the Citymapper app in 2017. It response to real-time transportation demand, utilised the open data capacity to identify underserved urban areas, then partnered with minibus/ taxi drivers to run commuter routes at those identified areas.

Initial identification of service main sustainable benefits:

\begin{tabular}{ll}
\hline Societal benefits & Operation prioritised underserved urban area to promote equality of commute options (Hern, 2018). \\
\hline Economic benefits & $\begin{array}{l}\text { Affordable fix rate } f 3 \text { per journey that respond to real-time citizens' need of commute in } \\
\text { underserved area (Hern, 2018). }\end{array}$ \\
\hline $\begin{array}{l}\text { Environmental } \\
\text { benefits }\end{array}$ & Share transportation to ease congestion and pollution. (Ashtari, cited in Hern 2018) \\
\hline
\end{tabular}




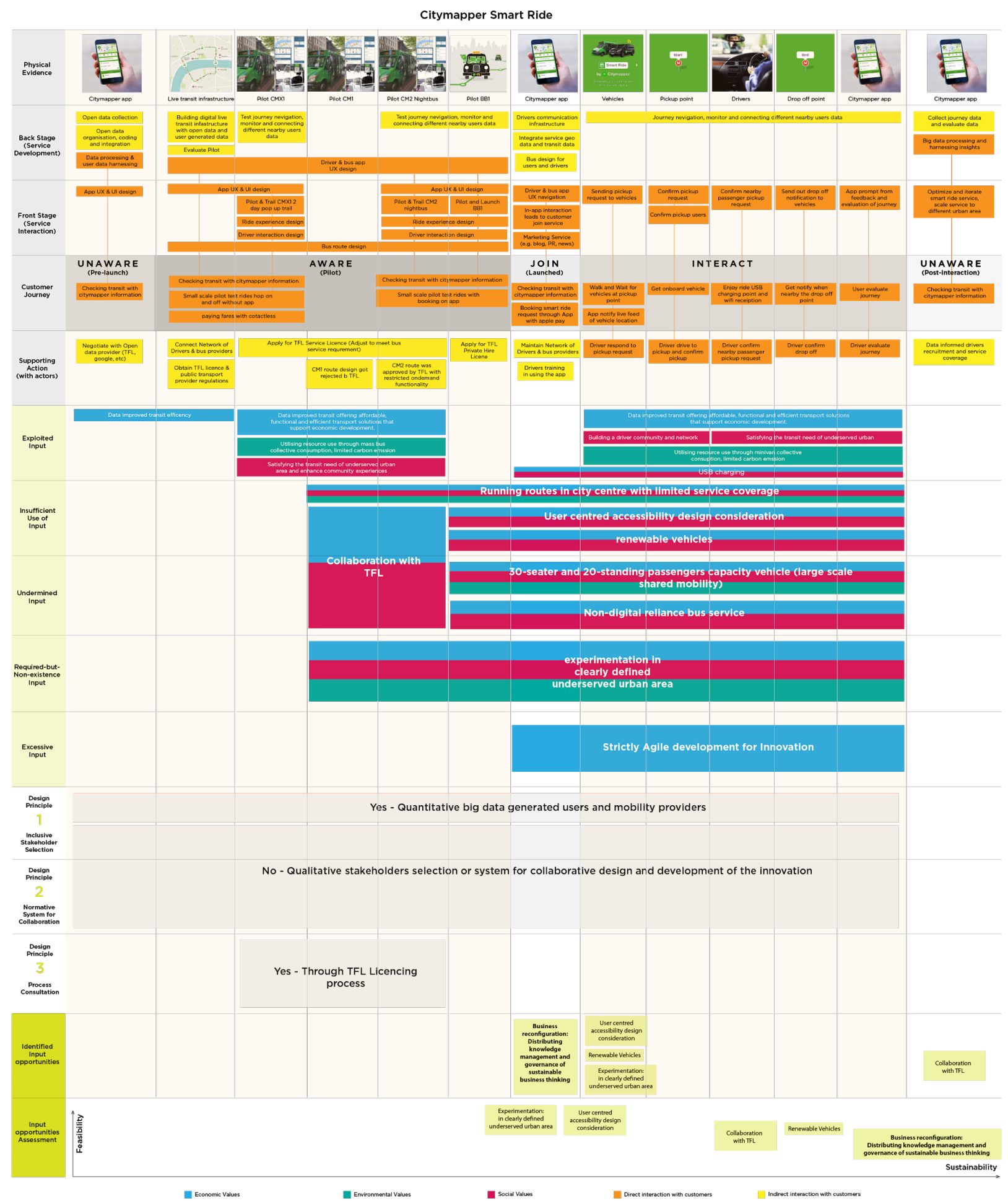

Figure 6. Citymapper Smart Ride Sustainability Evaluation Service Blueprint

\section{Identified Collaborations Principles for Sustainability}

The Sustainability Evaluation Service Blueprint (see figure 6) detailed that Citymapper Smart Ride has a unique business capacity of big data responsive network, generated from open transit database and Citymapper usergenerated data (Kobie, 2018a). With the built digital infrastructure, Citymapper can respond flexibly to instant change in transit needs in different areas. 
This concept was piloted with the testing 30-seater smartbus CMX1, designed with user-centred accessibility functions (Franklin-Wallis, 2017). The service applied for London Service Permission as CM1 and CM2 night smart-bus (Price, 2017). Yet they were either rejected and restrained from its' flexibility advantage of responding to real-time transportation demands (Citymapper, 2018a), due to Transport for London (TFL) bus regulations 1981 for fleets carries 9+ passengers (e.g. fixed numbers of bus route per day, fixed distance between fleets). "...It's not about a lack of desire, it's about changing the regulatory frameworks. At the moment it's a struggle to do this (Bown of Citymapper, quote in ARUP 2018)." This quote and its supporting report drawn the attention to a main challenge of outdated policy overriding positive public feedback generated in the piloting phase. Regulatory difficulties with TFL and government body caused Citymapper to forfeit the pilot concept of London bus service and iterate their service design (Citymapper, 2018a). They scaled down their fleet size from minibus to minivan, carrying 6 passengers per fleet to obtain a private hire licence from TFL (Topham, 2018a), enter the share ride market of Uber (Barber, 2018).

In the end, Citymapper launched Smart Ride work with a network of 500 self-employed drivers (suppliers), provided them training in using the Citymapper driver app to connect with the users, similar to other ride hiring platforms (McMullan, 2018). This concept was born out from the agile approach of working, which forms an experimental closed innovation strategy that aims to solve immediate problem under a rapid timeframe (Citymapper, 2018c). These results show that the development of Smart Ride (see in Table 7) does not appear to have evidence of process consultation initiatives with multiple actors beyond TFL licencing requirements. Inclusive stakeholder selection and collaboration was also absent from documentation. As for normative system of collaboration, it can be argued that the open source transportation and user generated quantitative data were used for determining underserved area route creation, but no qualitative stakeholder collaboration was identified. Therefore, collaboration for sustainability remained largely unexplored in the design and development process.

Table 7. Identified Collaboration Principles in Citymapper Smart Ride

\begin{tabular}{|c|c|}
\hline Design Principles & Example \\
\hline 1. Inclusive Stakeholder Selection & $x$ \\
\hline 2. Normative System for Collaboration & $\begin{array}{l}\text { Quantitative User generated underserved area route creation } \\
\qquad \text { (Citymapper, 2018a) }\end{array}$ \\
\hline 3. Process Consultation & Process consultation done under TFL requirements (Price, 2017). \\
\hline
\end{tabular}

\section{Identified Key Unexploited Input in Innovation}

This section extracted some key results from the Citymapper Sustainability Service Blueprint exercise (see figure 6). The unexploited inputs (table 8) discussed below were identified in the reviewed documents, reports and news articles.

Table 8. Identified Key Unexploited Input in Innovation

\begin{tabular}{ll}
\hline Unexploited Input & \\
\hline Undermined Input & $\begin{array}{l}\text { Downscaled Sustainable Impact through Bus to Minivan Iteration } \\
\text { The physical evidence of service operation journey (see figure 6) showed that the launch of } \\
\text { smart-ride minivan has undermined the sustainability benefits of smart-ride minibus. The } \\
\text { change in vehicle selection limited the user centred accessibility design of the ride } \\
\text { experiences, including accessible exit for disabled users and large display for signposting bus } \\
\text { stop arrivals (Tech Crunch, 2017). The down scale of the vehicles size also implies that more } \\
\text { minivans are needed to satisfy a certain number of passengers, increasing the pollution and } \\
\text { congestions on roads. This iteration also has turned the smart-ride into a digital exclusive }\end{array}$ \\
\hline
\end{tabular}


service, which is only accessible to people with a smartphone that has installed Citymapper's app.

Insufficiently used Input i. TFL Collaboration

The iteration also lacks strategic input from collaboration with external stakeholders, which are the results of lacking collaboration principles (e.g. inclusive stakeholder selection and normative system of collaboration). As seen in figure 6, TFL is a major decision maker that impacted Citymapper's service iterations. Therefore, it can be determined that collaboration with TFL was one of the earliest undermined and insufficiently used input in Citymapper's Smart Ride service development.

ii. Run routes in City Centre with limited coverage (Citymapper, 2018a)

Excessive Input Short cycle, Speed focused User-Centred Agile App Development Process (caused by lack of business-government strategy)

Required-but-NonExistent Input i. Lack of Business Government Strategy in User-Centred Agile App Development Process On the other hand, the agile development approach is also suspected to block potential Smart Ride sustainable benefits. Agile development approach is commonly adopted in software development industry for its' speed of delivery and customer centric feedback method (Conboy et al., 2011). Although this iterative method has delivered speedy results for Citymapper in their public transit information service, creating smart ride service under agile development approach forced Citymapper to work in short cycles (Citymapper, 2018a, 2018b, 2018c). For example, the Smart Ride innovation team would then redevelop the service experience to problem solve the immediate regulatory feedback with technological solution, instead of strategically planning for business government shared objectives (Conboy et al.,2011).

ii. Experimentation in clearly defined underserved urban area

TFL denied the CM1 route based on the disturbing citizen in busy city centre (Price, 2017).

\section{Ford Chariot Commuter Bus}

Table 9. Ford Chariot Commuter Bus Operation Profile

\section{Background:}

The Chariot Commuter Bus is a smart commute service app founded by Ali Vahabzadeh at San Francisco in 2014 (Brownstein, 2014), later on acquired by Ford in 2016 (Etherington, 2016). It is a first and last mile transport solution that supplement public transit trains and bus routes (Topham, 2018b). It connects users in the underserved urban area to their nearest public transport option (Smith, 2018a).

Initial identification of service main sustainability benefits:

Societal benefits Operation prioritised underserved urban area to promote equality of commute options (Smith, 2018a)

\begin{tabular}{ll}
\hline Economic benefits & Affordable fix rate $£ 2.4$ per journey that has a guaranteed seat on the minibus (Topham, 2018b). \\
\hline $\begin{array}{l}\text { Environmental } \\
\text { benefits }\end{array}$ & Share transportation to ease congestion and pollution. (Chariot, 2018b) \\
\hline
\end{tabular}




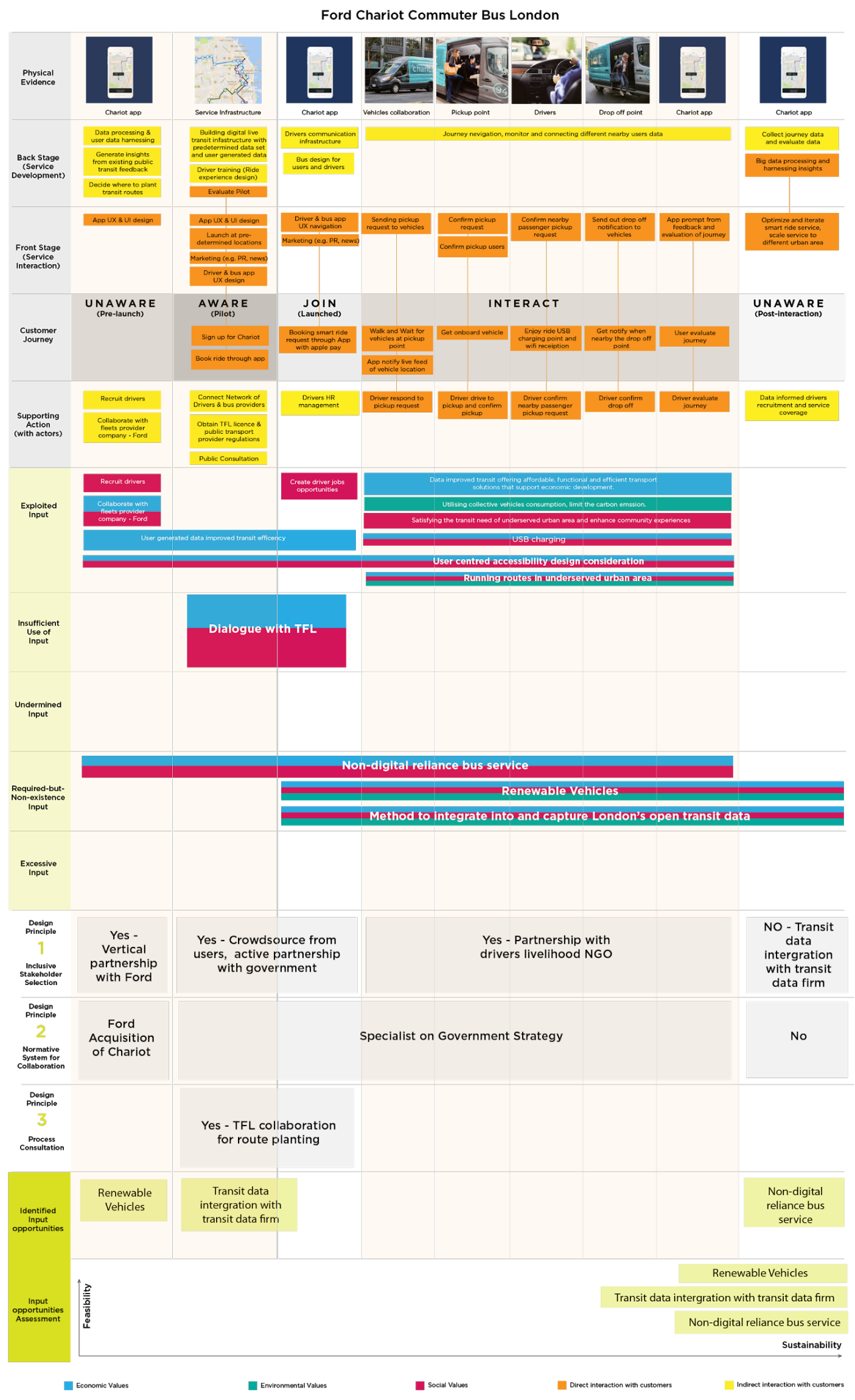

Figure 7. Ford Chariot Sustainability Evaluation Service Blueprint 


\section{Identified Collaborations Principles for Sustainability}

The Service Sustainable Evaluation Blueprint (see figure 7) documented that Chariot, similar to Citymapper, also crowdsource for their route creation, desired-pickup and destination via the aggregated user interaction in Chariot's app (Etherington, 2018). However, without the advantages of having a public transit information app, like Google Maps or Citymapper, the process of aggregating user generated data was relatively difficult for Chariot.

Chariot was a proven successful in Bay area, San Francisco, which has led to the acquisition of Ford Smart Mobility. With Ford's help, the start-up expanded in different international cities (Etherington, 2018). Vahabzadeh, founder of Chariot stated in an interview that "It became very clear very early on that Chariot would be able to leverage Ford's expertise in logistics and vehicle and operations to take Chariot and make this a global service, beyond just the Bay area" (Etherington, 2018). This noticeable strategic corporate start-up collaboration taken early advantages of Ford's expertise. It also utilised its' business-governments relationships in multi-countries for operation expansion (Campbell, 2017), fast tracked Chariot's global development. While Ford's expertise secured the collaboration between TFL and Ford Chariot, collaboration difficulties with TFL continues to show. According to the Guardian, Chariot applied for six routes in underserved London areas, but only four were granted by TFL (Wilding, 2018). These events offer more insight into the cautious nature of public-private collaboration.

Researchers of mobility (Lindsay, quoted in Wilding 2018) explained that there are hidden concerns over investors increasingly investing in new and innovative digital transport solutions instead of public transport solutions, triggering possibility of 'ridesharing apps leading to a cycle of cataclysmic disinvestment'. Greg Lindsay of the NeCities Foundation (cited in Wilding, 2018) also raised concern about private transport network: 'They will try to siphon off the most profitable customers and leave public transport a rump service'. These quotes outlined the rivalry positions of public and private transit and the potential implication of social divide through transport options (Wilding, 2018; Topham, 2018c). Drawing the attention to an overall mobility challenge: How can private operators, like Chariot help to create a balance and synergistic system, instead of competitive relationship of private and public transit?

In this case study, Chariot has collaborated with its' vehicle supplier Ford, who's priorities are to develop partnerships with local government (see table 10). It utilised user generated data and strategic Ford partnerships in creating and expanding its' operation. However, similar to Citymapper, there was little evidence to show the process consultation beyond the TFL requirements. Therefore, collaboration principles were not fully revealed in the investigation.

Table 10. Identified Collaboration Principles in Ford Chariot

\begin{tabular}{ccc}
\hline \multicolumn{2}{c}{ Design Principles } & Example \\
\hline 1. & Inclusive Stakeholder Selection & Ford strategic alliance lead to US local government partnership and UK \\
expansion. (Etherington, 2018)
\end{tabular}

\section{Identified Unexploited Input in Innovation}

This section extracted some key results from the Ford Chariot Sustainability Service Blueprint exercise (see figure 7). The key unexploited input (table 11) discussed below were identified in the reviewed documents, reports and news articles. 


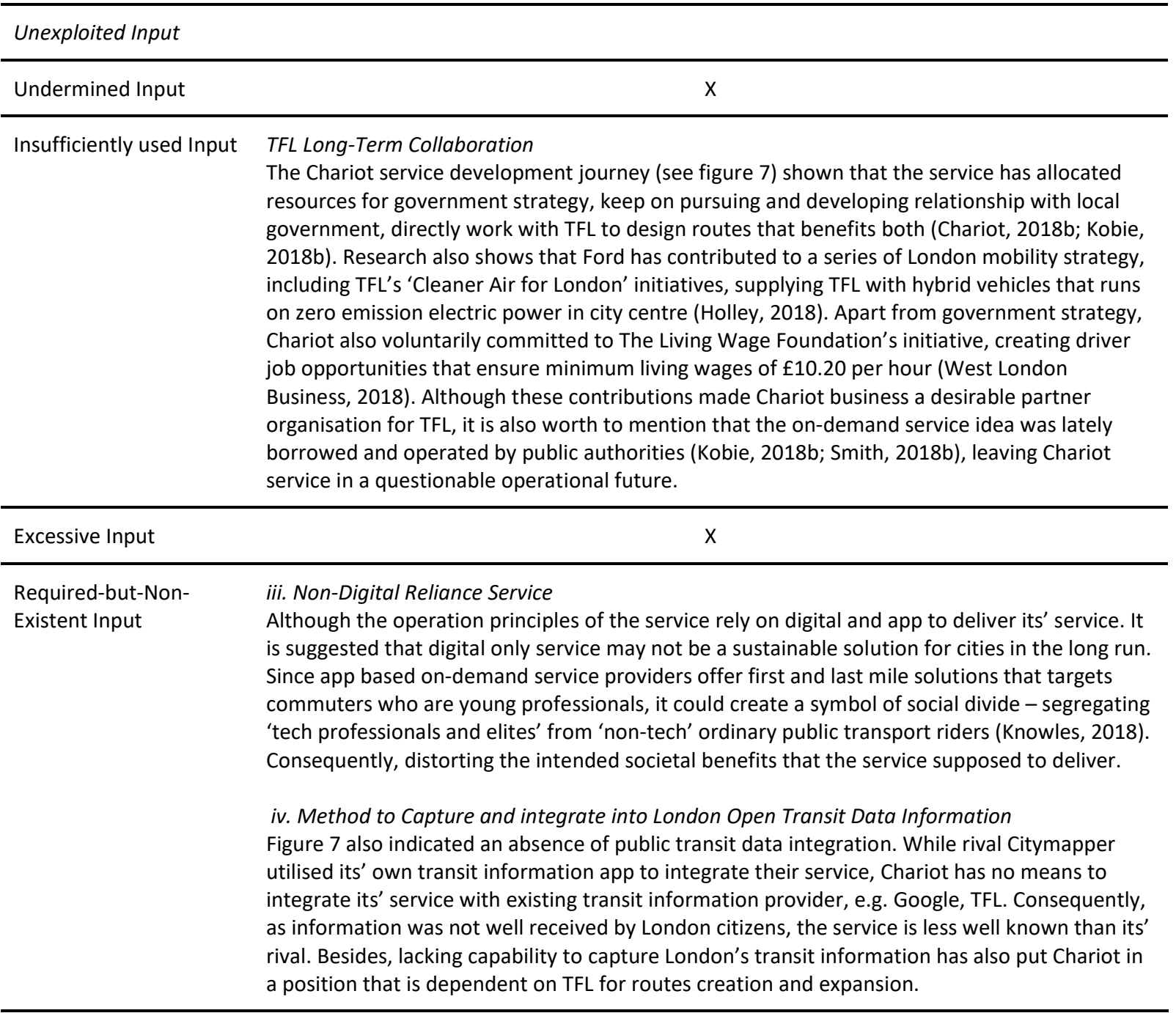

\section{Input Opportunity Assessments}

The Citymapper Smart Ride and Ford Chariot case studies combined, offer learning points for sharing mobility services that aim to tackle sustainability challenges. While Citymapper Smart Ride uses agile experimentation approach to develop their service and highlighted the transport policy challenges in driving sustainable development with sharing mobility services, Ford Chariot revealed the macro challenge in private-public collaboration for developing holistic mobility ecosystem for sustainability. As the purpose was not to evaluate the effectiveness of both cases, the insights generated from the two case studies above are to provide means for discussing how innovation opportunities for sustainability can be explored under different service development and operation process. By doing so, the insights help to evaluate the implication of using service blueprint to sense-make sustainability related issues incurred in mobility service operation. 


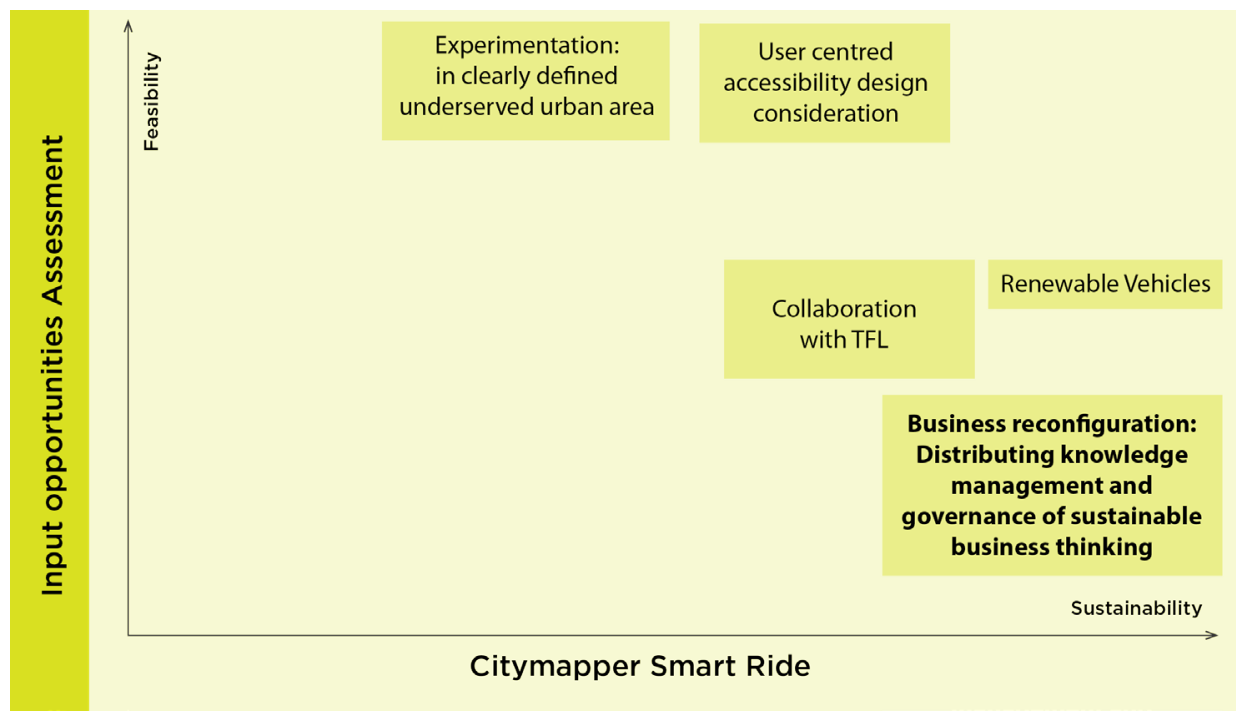

Figure 8. Citymapper Smart Ride Input Opportunities Assessment

According to the identified insights in the Citymapper smart ride case study (see table 7 \& 8.), Citymapper has complex unexploited inputs related both on collaboration and TBL value. It showed that Smart Ride has made a lot of effort to meet the TFL licence criteria, including compromising their user-centred design, which led the business into an unsustainably demanding short-cycle development process. According to Inigo et al. (2017), radical innovation, like Smart Ride, would require reconfiguration (see figure 8) involving not only product service design, but business model reconfiguration, such as distribution of knowledge management (e.g. knowledge exchange and collaboration with TFL) and governance of sustainable business thinking (e.g. Smart Ride service operation managerial capability). These are all input opportunities worth considering for sharing mobility services models that aim to tackle sustainability challenges.

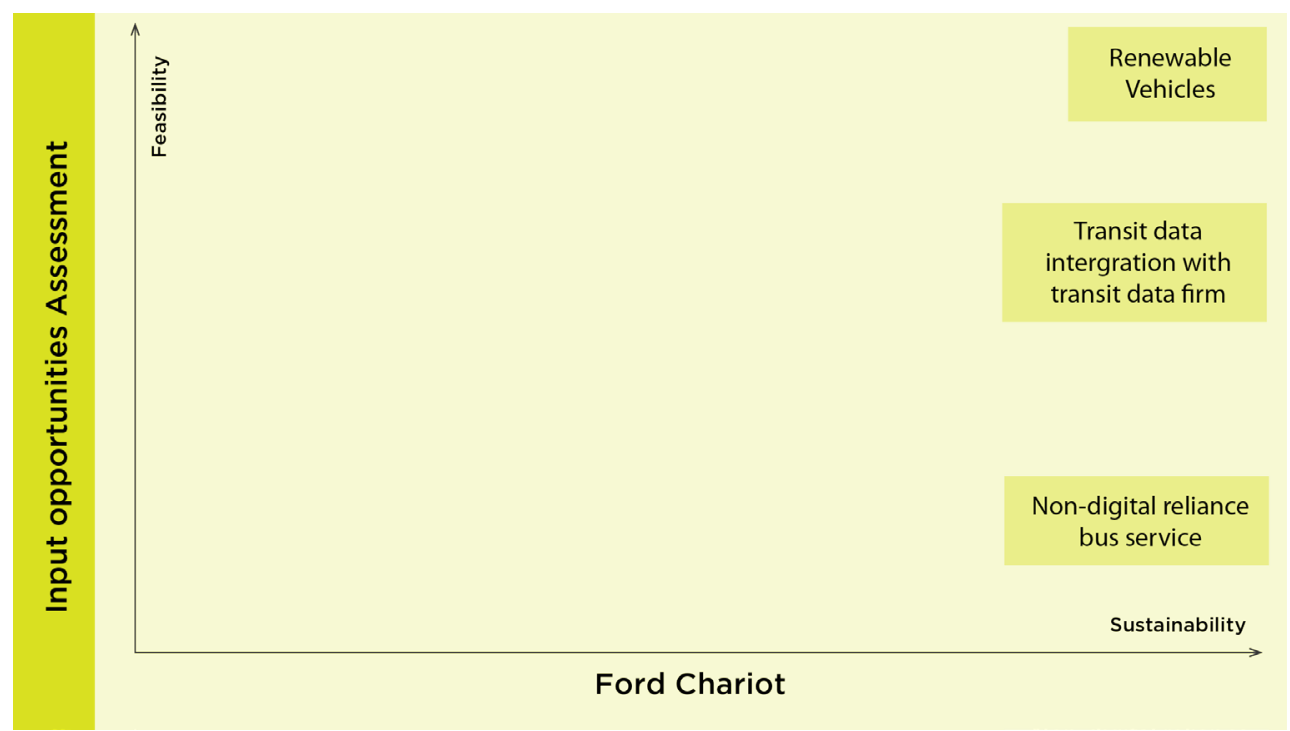

Figure 9. Citymapper Smart Ride Input Opportunities Assessment

According to the identified insights in the Ford Chariot case study (see table 10 \& 11), Ford Chariot's unexploited inputs were all technical inputs that can be improved with Ford's capability to embrace new partnership. Therefore, the input opportunities assessment (see figure 9) determine that Ford's partnership 
capability increase the viability of transit data integration with transit data firm. While increased research and development capacity of Ford's renewable vehicles (Holley, 2018), could imply it is highly possible for Ford Chariot to operate their service on renewable fleets. Last but not least, non-digital reliance service may not be a feasible option for an app-based service company like Ford Chariot.

\section{Discussion}

This section analyses and discusses the findings according to the development of the blueprint and the two case studies, stating the contribution of the work to inform future research on sustainability evaluation, as well as the topic of sharing mobility service as sustainable innovation.

\section{Sharing Mobility Service as Sustainable Innovation}

\section{Agile New Service Development (NSD) and Sustainable Innovation Incompatibility}

The Smart Ride case study showcased a potential incompatibility in using Agile development process to iterate sustainable service, where regulatory feedback was answered with service technological solution, instead of strategically planning for business-government shared objectives (Conboy et al.,2011). While the agile development enabled the rapid progress of information technology (e.g. Citymapper's responsive transit data network), initiated the emergence of knowledge-based sustainable service concept - Citymapper Smart Ride. However, transforming mobility for sustainability builds on not only the result of the agile NSD and iteration with user feedback, but the sustainable value creation amongst the collaborative innovation networks (Elke den Ouden, 2012). This means the interdependent stakeholders ranging from TFL, Citymapper, drivers, users to local community members, needs to integrate their knowledge and expertise to create TBL values. This takes more than agile NSD and iteration on product and service feedback, but a shared working process, principles and tools to allow all the relevant stakeholders to work together constructively to test and build sustainable innovation that provide value at different levels - for the users, for the organisations and for society at large.

\section{Private-Public Dilemma in Collaboration for Sustainability}

Approaching sustainable innovation with service design and planning approach means considering how collaboration was conducted at each level and each stage of the service operation. From the first stage of validating service blueprint evaluation criteria to the examination of case studies, private and public actors hold diverse perspectives and viewpoints on collaboration process consultation in general. In the Mobility Innovation case study, the investigation reveals that while Chariot business is a desirable partner organisation for TFL, the on-demand service idea was lately borrowed and operated by public authorities (Kobie, 2018b; Smith, 2018b), leaving Chariot service in a questionable operational future. This event proven that while public process consultation allows public society and communities to feedback and improve the service innovation, it is unsustainable for business to do so without any protective measure on their rights to the service innovation. This further explained private actors' practice of setting process and ways of working as a self-protective measure, while public actors are in favour of process consultation as a core principle and suggested that it is part of the best practice.

Curșeu and Schruijer (2017) argued that these types of collaboration conflicts happened due to the distrust, unsafe and collusive dynamics of the collaboration. This further emphasis on building collaboration relationship on a normative system, where shared process and ways of working are established. These shared guidelines should aim to enable the emergence of trust and prevent collusive dynamics, building a constructive and safe multiparty collaborative system. 


\section{Sustainability Evaluation in Service-Based Sustainable Business Model Innovation}

\section{The Concept of Sustainability 'Value' in Evaluating Service Operations}

Value is a term that was used throughout the literature and in the first iteration of the blueprint, yet feedback from actors indicated that the concept of value is difficult to use in practical operation evaluation. According to Yang et al. (2017), the concept of value was developed from Richardson (2008) and Amit \& Zott (2012), which has established the academic theory building. Since this research aim to develop practical sustainability evaluation tools through service blueprint, requiring participatory research with non-academic actors who involved in the service operation. Therefore, using the term 'value' in a service blueprint would not be apprehensible for actors involved in the evaluation process.

Nonetheless, the concept of value defines things or activities exploited in the production process that have created and improved business economic benefits (e.g. profit margin), extended from Porter's concept of value chain (1985). However, this research focus on 'unexploited activities', which have not created, but have potential to bring society and environment benefit - which is different from economic benefits as well. Through validation with industry experts, interviewees expressed that engaging stakeholders in sustainable value creations needs simple facilitative tools and language. Therefore, it was suggested to simplify sustainability 'values' to sustainability 'benefits', clarifies the purpose to create 'societal and environmental benefits', instead of simply 'economic benefits'. It was also suggested to simplify 'uncaptured values' to 'unexploited inputs', clarifies the consideration of 'unexploited activities', instead of 'exploited economic benefits - value'.

\section{Role of Sustainability Evaluation Service Blueprint in Sustainable Innovation}

Designing service blueprint with evaluation criteria of sustainable benefits and sustainable collaboration, allow us to identify insights for optimising the overall service offering for sustainability. It also informs the new service development (NSD) activities (Yu and Sangiorgi, 2017), especially relating to the organisational and managerial activities for sustainability. Together with service blueprint's capabilities to visualising userinteraction, relationship analysis and service experiences through multi-actors perspectives. The Service Sustainability Evaluation Tool stimulate comprehensive service operation evaluation against sustainability, to review the optic of sharing mobility as service-based sustainable innovation.

The two case studies above showcased how sustainability evaluation service blueprint can be used to contextualise the holistic service offer and operations development. For instance, the sustainability benefits criteria revealed that both services were driven by clear economic benefits, with either blurry and destroyed social and environmental benefits as the NSD activities progress into service operational and managerial activities. On the other hand, the sustainable collaboration criteria illustrated complex operational activities with multiple actors involved (Chou, Chen and Conley, 2012; Baldassarre et al., 2017; Prendeville and Bocken, 2017; Tukker, 2015), such as collaboration with TFL and community members, managing drivers, etc. Through mapping out stakeholders and their activities, service blueprint immediately exposed the unexploited input (e.g. electric fleet choice) and stakeholder impacts (e.g. social divide created through digital and non-digital commuters) in the rideshare service operation, opened up a clearer vision of the holistic service operation needs. The visibility enabled by this tool showcases its' value for practitioners to explore and employ service design thinking and practice for the advancement of sustainable innovation (Prendeville and Bockon, 2017).

\section{Conclusion}

This study contributes to the service design and innovation (including PSS research stream) and sustainability literatures. The synergies between sustainable values, collaborative principles for sustainability and service design tool construct a service operation sustainability evaluation blueprint. It draws on two explorative case studies and therefore there are some limitation to the conclusions drawn. By illustrating how service operation planning tool - service blueprint can facilitate the sustainability evaluation processes for sharing services, this research explored the potential of using service blueprint to improve the service sustainability by identifying sustainable collaboration principles and eliminating unexploited inputs in existing service. It repositions service design tool - service blueprint as a constructive facilitation tool for analysing sustainable service innovation. 
Most importantly, it enables service designers to map out all the interactions related with delivering a sustainable service and to determine feasibility of implementing those opportunities, leading to future possibilities for designing organisational interactions and policies for sustainable service innovations.

As the concepts of sustainable business model transform into concrete products and services, service designers and service developers need to learn how to evaluate and iterate for TBL benefits optimisation in the NSD activities, in order to build sustainable service operation journey. Further work is recommended to explore how to use the sustainability evaluation service blueprint to facilitate and improve TBL value creation in service operations of an organisation, which engage in a service-based innovation for sustainability. Learnings from an in-depth case study will further the use of service design practices, methods and tools, as strategy to build tangible Sustainable NSD process upon sustainability business model innovation theory.

\section{Acknowledgment}

We would like to thank British Standard Institute (BSI) and all the participants for their assistance, support and insights in this study.

\section{References}

Amit, R., and Zott, C. (2012). Creating value through business model innovation. MIT Sloan Management Review 53(3): 41-49.

ARUP (2018). Rethinking Urban Mobility: Three questions that will shape the future of transport in cities. [ebook] London: The London Transport Museum Interchange programme. Available at: https://www.Itmuseum.co.uk/assets/Rethinking_Urban_Mobility_Report_copy.pdf [Accessed 20 Jul. 2018].

Bailey, L. (2010). Case Study Research. SAGE Publications, Inc. [ebook] Available at: http://dx.doi.org/10.4135/9781412958806.n59 [Accessed 4 May 2018].

Barber, L. (2018). Citymapper's launched a carpooling service that's a minicab-bus hybrid. [online] Cityam.com. Available at: http://www.cityam.com/281002/citymappers-launched-mincab-bus-hybrid-carpooling-service [Accessed 20 Jul. 2018].

Battistella, C., \& Nonino, F. (2012). Exploring the impact of motivations on the attraction of innovation roles in open innovation web-based platforms. Production Planning \& Control, 24(2-3), 226-245. doi: 10.1080/09537287.2011.647876

Baldassarre, B., Calabretta, G., Bocken, N., \& Jaskiewicz, T. (2017). Bridging sustainable business model innovation and user-driven innovation: A process for sustainable value proposition design. Journal Of Cleaner Production, 147, 175-186. doi: 10.1016/j.jclepro.2017.01.081

Bocken, N., Short, S., Rana, P., \& Evans, S. (2013). A value mapping tool for sustainable business modelling. Corporate Governance: The International Journal Of Business In Society, 13(5), 482-497. doi: 10.1108/cg-062013-0078

Botsman, R., Rogers, R. (2010). What's Mine is Yours: How Collaborative Consumption is Changing the Way We Live. Collins, London, UK.

Boons, F., \& Mendoza, A. (2010). Constructing sustainable palm oil: how actors define sustainability. Journal Of Cleaner Production, 18(16-17), 1686-1695. doi: 10.1016/j.jclepro.2010.07.003

Boons, F., Montalvo, C., Quist, J. and Wagner, M. (2013). Sustainable innovation, business models and economic performance: an overview. Journal of Cleaner Production, 45, pp.1-8.

Brownstein, R. (2014). Forget dating apps. These millennials want to save the world. [online] CNNMoney. Available at: https://money.cnn.com/2014/10/30/smallbusiness/tumml-next-economy-millennials/index.html [Accessed 24 Jul. 2018]. 
Calabrese, A., Castaldi, C., Forte, G., \& Levialdi, N. (2018). Sustainability-oriented service innovation: An emerging research field. Journal Of Cleaner Production, 193, 533-548. doi: 10.1016/j.jclepro.2018.05.073

Campbell, P. (2017). Ford plans to take Chariot into London commuting battle | Financial Times. [online] Ft.com. Available at: https://www.ft.com/content/073dce74-cede-11e7-b781-794ce08b24dc [Accessed 24 Jul. 2018].

Charter, M. and Clark, T. (2007). Sustainable Innovation: Key conclusions from Sustainable Innovation Conferences 2003-2006 organised by The Centre for Sustainable Design. [ebook] The Centre for Sustainable Design: University College for the Creative Arts. Available at:

http://cfsd.org.uk/Sustainable\%20Innovation/Sustainable_Innovation_report.pdf [Accessed 22 Mar. 2018].

Chariot (2018a). Chariot - About Us. [online] Chariot.com. Available at: https://www.chariot.com/about [Accessed 6 Jul. 2018].

Chariot (2018b). Chariot Shuttle Service Comes to Europe, First Stop London with Four Routes Designed to Ease Travel for Commuters | Great Britain | Ford Media Center. [online] Media.ford.com. Available at: https://media.ford.com/content/fordmedia/feu/gb/en/news/2018/02/01/chariot-shuttle-service-comes-toeurope--first-stop-london-with-.html [Accessed 24 Jul. 2018].

Choo, C. (1996). The knowing organization: How organizations use information to construct meaning, create knowledge and make decisions. International Journal Of Information Management, 16(5), 329-340. doi: 10.1016/0268-4012(96)00020-5

Choo, C. (2002). Sensemaking, Knowledge Creation, and Decision Making: Organizational Knowing as Emergent Strategy. In C. Choo and N. Bontis (Eds.), The Strategic Management of Intellectual Capital and Organizational Knowledge. Oxford Univ Press.

Charter, M., Gray, C., Clark, T., Woolman, T. (2008). Review: the role of business in realising sustainable consumption and production. In: Tukker, A., Charter, M., Vezzoli, C., Stø, E., Andersen, M.M. (Eds.), Perspectives on Radical Changes to Sustainable Consumption and Production 1. System Innovation for Sustainability. Greenleaf, Sheffield, pp. $46 \mathrm{e} 69$.

Chou, C., Chen, C. and Conley, C. (2012). A systematic approach to generate service model for sustainability. Journal of Cleaner Production, 29-30, pp.173-187.

Citymapper (2018a). Good Bus (Part 1/3) - Citymapper - Medium. [online] Medium. Available at: https://medium.com/citymapper/good-bus-part-1-3-77d65e6f8ce3 [Accessed 19 Jun. 2018].

Citymapper (2018b). Bad Bus (Part 2/3) - Citymapper - Medium. [online] Medium. Available at: https://medium.com/citymapper/bad-bus-part-2-3-e22f8824d3b8 [Accessed 19 Jun. 2018].

Citymapper (2018c). The Responsive Network (Part 3/3) - Citymapper - Medium. [online] Medium. Available at: https://medium.com/citymapper/the-responsive-network-part-3-3-f9d8394d84f3 [Accessed 23 Jul. 2018].

Cohen, B. and Kietzmann, J. (2014). Ride On! Mobility Business Models for the Sharing Economy. Organization \& Environment, 27(3), pp.279-296.

Cox, M., Arnold, G. and Villamayor Tomás, S. (2010). A Review of Design Principles for Community-based Natural Resource Management. Ecology and Society, 15(4).

Conboy, K., Coyle, S., Wang, X. and Pikkarainen, M. (2011). People over Process: Key Challenges in Agile Development. IEEE Software, 28(4), pp.48-57.

Curșeu, P. and Schruijer, S. (2017). Stakeholder diversity and the comprehensiveness of sustainability decisions: the role of collaboration and conflict. Current Opinion in Environmental Sustainability, 28, pp.114120.

den Hertog, P., van der Aa, W., \& de Jong, M. (2010). Capabilities for managing service innovation: towards a conceptual framework. Journal Of Service Management, 21(4), 490-514. doi: 10.1108/09564231011066123

den Hertog, P. (2000). Knowledge-Intensive Business Services as Co-Producers of Innovation. International Journal Of Innovation Management, 4(4), 491-528. doi: 10.1016/s1363-9196(00)00024-x

Dorst, K. (2015). Frame innovation. Cambridge, Massachusetts: The MIT Press. 
Edvardsson, Bo, Anders Gustafsson, and Inger Roos (2005). Service Portraits in Service Research: A Critical Review. International Journal of Service Industry Management, 16 (1), 107-121.

Elkington, J. (1998). Accounting for the Triple Bottom Line. Measuring Business Excellence, 2(3), 18-22. doi: 10.1108/eb025539

Elkington, J. (1994). Towards the Sustainable Corporation: Win-Win-Win Business Strategies for Sustainable Development. California Management Review, 36(2), 90-100. doi: 10.2307/41165746

Etherington, D. (2016). Ford Smart Mobility acquires Chariot to boost its smart city transit plans. [online] TechCrunch. Available at: https://techcrunch.com/2016/09/09/ford-mobility-solutions-acquires-chariot/ [Accessed 24 Jul. 2018].

Evans, S., Rana, P., and Short, S. W. (2014). Final set of tools \& methods that enable analysis of future oriented, novel, sustainable, value adding business-models and valuenetworks. Deliverable D2.6, Project 262931, SustainValue: Sustainable value creation in manufacturing networks.

http://www.sustainvalue.eu/publications/D2_6_Final_v2.pdf

Fadeeva, Z. (2005). Promise of sustainability collaboration-potential fulfilled?. Journal of Cleaner Production, 13(2), pp.165-174.

Franklin-Wallis, O. (2017). Citymapper's next stop? Launching a London bus. [online] Wired.co.uk. Available at: https://www.wired.co.uk/article/citymapper-london-bus-cmx1 [Accessed 20 Jul. 2018].

Hern, A. (2018). Citymapper launches bus-taxi hybrid Smart Ride in London. [online] the Guardian. Available at: https://www.theguardian.com/technology/2018/feb/21/citymapper-launches-bus-taxi-hybrid-smart-ridelondon-transit-app [Accessed 20 Jul. 2018].

Holley, M. (2018). Chariot starts - but TfL restricts trial. [online] Route One. Available at: http://www.routeone.net/articles/Chariot_starts__but_TfL_restricts_trial [Accessed 26 Jul. 2018].

Inigo, E., Albareda, L. and Ritala, P. (2017). Business model innovation for sustainability: exploring evolutionary and radical approaches through dynamic capabilities. Industry and Innovation, 24(5), pp.515-542.

Janssen, M., Castaldi, C., Alexiev, A., Den Hertog, P. (2015). Exploring a multidimensional approach to service innovation. In: The Handbook of Service Innovation (Pp. 91e108). Springer, London.

Kobie, N. (2018a). The rules refuse to bend as Citymapper moves to disrupt London transport. [online] Wired.co.uk. Available at: https://www.wired.co.uk/article/citymapper-smart-ride-ceo-smart-bus-makemoney [Accessed 20 Jul. 2018].

Knowles, K. (2018). [online] Forbes.com. Available at:

https://www.forbes.com/sites/kittyknowles/2018/01/31/tfl-ford-chariot-app-citymapper-gett-taxi-bus-routesuber-london-transport/\#fb060c3f0a80 [Accessed 26 Jul. 2018].

Krippendorff, K. (2007). The semantic turn: A new foundation for design. Artifact, 1(1), 56-59. doi: $10.1080 / 17493460600844157$

Ouden, E. (2012). Innovation design. London: Springer Verlag London Limited.

Plepys, A., Heiskanen, E., \& Mont, O. (2015). European policy approaches to promote servicizing. Journal Of Cleaner Production, 97, 117-123. doi: 10.1016/j.jclepro.2014.04.029

Porter, Michael E. (1985). Technology and Competitive Advantage, Journal of Business Strategy, Vol. 5 Issue: 3 , pp.60-78, https://doi.org/10.1108/eb039075

Prendeville, S. and Bocken, N. (2017). Sustainable Business Models through Service Design. Procedia Manufacturing, 8, pp.292-299.

Price, R. (2017). Citymapper has been given permission to launch a night bus in East London. [online] Business Insider. Available at: http://uk.businessinsider.com/citymapper-granted-permission-tfl-cm2-night-bus-eastlondon-2017-7 [Accessed 20 Jul. 2018].

Rauter, R., Vorbach, E. and Baumgartner, R. (2017). Is open innovation supporting sustainable innovation? Findings based on a systematic, explorative analysis of existing literature. International Journal of Innovation and Sustainable Development, 11(2/3), p.249. 
Richardson, J. (2008). The business model: An integrative frame- work for strategy execution. Strategic Change 17:133-44.

Rose, E. (2017). Citymapper launches 'smart buses' in London to 'reinvent' bus service. [online] Evening Standard. Available at: https://www.standard.co.uk/news/transport/citymapper-launches-smart-buses-inlondon-in-bid-to-reinvent-bus-service-a3533641.html [Accessed 19 Jun. 2018].

Sangiorgi, D., Fogg, H., Johnson, S., Maguire, G., Caron A., \& Vijakumar, L. (2012). Think Services. Supporting manufacturing companies in their move toward services. In Service Design and Innovation Conference, ServDes2012, (pp. 253-263). Helsinki, Finland.

Schmiedgen, J. and Management, C. (2011) Innovating User Value The Interrelations of Business Model Innovation, Design (Thinking) and the Production of Meaning - A Status-quo of the Current State of Research, Thesis - M.A. of Arts, Zeppelin University.

Schofield, H. (2014). Short-let apartments spark Paris row as Airbnb thrives [Online]. BBC News Available http://www.bbc.co.uk/news/world-europe-30580295 [Accessed 23 Mar. 2018]. Production of Meaning, Management, vol. 2011, pp. 1-140.

Segelström, F. (2013). Stakeholder Engagement for Service Design: How service designers identify and communicate insights (PhD dissertation). Linköping. https://doi.org/10.3384/diss.diva-97320

Smith, R. (2018a). Ford's Chariot commuter shuttle bus service starts on four London routes. [online] Cityam.com. Available at: http://www.cityam.com/279709/fords-chariot-commuter-shuttle-bus-service-hasjust-started [Accessed 24 Jul. 2018].

Smith, R. (2018b). TfL looking to trial "demand responsive" bus service in outer London. [online] Cityam.com. Available at: http://www.cityam.com/282842/tfl-trial-demand-responsive-bus-service-after-fords-chariot [Accessed 26 Jul. 2018].

Stickdorn, M., Schneider, J. and Andrews, K. (2011). This is service design thinking. Amsterdam: BIS Publishers. Shostack G. L. (1984). Designing services that deliver. Harvard Business Review, Vol. 62, No. 1, 1984, pp. 133139.

Teece, D. J. (2017). Business models and dynamic capabilities. Long Range Planning (in press), https://doi.org/10.1016/i.Irp.2017.06.007

Tech Crunch (2017). Citymapper's Smartbus could be the bus of the future. [video] Available at: https://www.youtube.com/watch?v=8crJqoHqzrU [Accessed 23 Jul. 2018].

Topham, G. (2018a). Oxford buses turn to Uber-style apps in on-demand experiment. [online] the Guardian. Available at: https://www.theguardian.com/business/2018/jun/29/oxford-buses-turn-to-uber-style-apps-inon-demand-experiment?page=with\%3Aimg-2 [Accessed $20 \mathrm{Jul}$. 2018].

Topham, G. (2018b). Your Chariot awaits: shuttle bus service gets green light in London. [online] the Guardian. Available at: https://www.theguardian.com/uk-news/2018/jan/29/fords-trial-minibus-ride-sharing-scheme-tolaunch-in-london [Accessed 24 Jul. 2018].

Topham, G. (2018c). TfL facing near $£ 1 b n$ deficit next year after journey numbers fall. [online] the Guardian. Available at: https://www.theguardian.com/uk-news/2018/feb/12/fall-in-journeys-leaves-tfl-facing-near-1bndeficit-next-year [Accessed 26 Jul. 2018].

Tukker, A. (2015). Product services for a resource-efficient and circular economy - a review. Journal of Cleaner Production, 97, pp.76-91.

Martin, C. (2016). The sharing economy: A Pathway to Sustainability or a Nightmarish form of Neoliberal Capitalism?. Ecological Economics, 121, pp.149-159.

McMullan, T. (2018). Citymapper's Smart Ride is an eight-seater Uber-style taxi... just don't call it a bus. [online] Alphr. Available at: http://www.alphr.com/life-culture/1008580/citymapper-smart-ride-uber-buslondon [Accessed 20 Jul. 2018].

Merlin, S., Eleni, A., (2018). Improving journeys by opening data: the case of Transport for London (TfL), The Bottom Line, Vol. 31 Issue: 1, pp.2-15, https://doi.org/10.1108/BL-12-2017-0035 
Mezger, F. (2014). Toward a Capability-based Conceptualization of Business Model Innovation: Insights from an Explorative Study. R\&D Management 44 (5): 429-449.

Morozov, E. (2013). The 'sharing economy' undermines workers rights [Online]. Available:

http://evgenymorozov.tumblr.com/post/64038831400/the-sharing-economyundermines-workers-rights [Accessed 23 Mar. 2018].

West London Business (2018). Chariot Shuttle Service Comes to Europe | West London Business. [online] West London Business. Available at: https://www.westlondon.com/chariot-shuttle-service-comes-europe/ [Accessed 26 Jul. 2018].

Wilding, M. (2018). Private companies want to replace public transport. Should we let them?. [online] the Guardian. Available at: https://www.theguardian.com/cities/2018/mar/29/public-transport-transit-privatecompanies-citymapper-uber-whim-smart-buses [Accessed 25 Jul. 2018].

van Veggel, R. J. (2005). Where the Two Sides of Ethnography Collide. Design Issues, 21(3), 3-16.

Vargo, Stephen L. and Robert F. Lusch (2008a). From Goods to Service(s): Divergences and Convergences of Logics. Industrial Marketing Management, 37 (3), 254-259.

Verganti, R. (2011). Radical Design and Technology Epiphanies: A New Focus for Research on Design Management. Journal of Product Innovation Management, 28(3), pp.384-388.

Verganti, R. (2014). Design-driven innovation. Boston, Mass.: Harvard Business Press.

Vezzoli, C., Ceschin, F., Diehl, J., \& Kohtala, C. (2015). New design challenges to widely implement 'Sustainable Product-Service Systems'. Journal Of Cleaner Production, 97, 1-12. doi: 10.1016/j.jclepro.2015.02.061

Yang, M. (2016). Sustainable Value Analysis for Product-Service Systems (Doctoral thesis). https://doi.org/10.17863/CAM.13773

Yang, M., Vladimirova, D., \& Evans, S. (2017). Creating and Capturing Value Through Sustainability. ResearchTechnology Management, 60(3), 30-39. doi: 10.1080/08956308.2017.1301001

Yin, R.K. (2003). Case Study Research Design and Methods, Sage, Newbury Park, CA, Applied Social Research Methods Series.

Yu, E. and Sangiorgi, D. (2017). Service Design as an Approach to Implement the Value Cocreation Perspective in New Service Development. Journal of Service Research, 21(1), pp.40-58. 